\title{
George Mason
}

George Mason, one of the pioneers of thoracic surgery in this country, died in Canberra in March 1971, while on world tour. A North countryman, born and bred, he founded and developed the thoracic centre at Shotley Bridge near Newcastle with the same persistence and efficiency that characterized all his activities.

In his early days, with his friend Laurence O'Shaughnessy, he was one of the group that originated the Society of Thoracic Surgeons of Great Britain and Ireland. At the first meeting in Newcastle this small nucleus of 20 to 30 members had little idea as to the expansion that would occur in the specialty, but when the membership had grown to ten times the original figure it was George Mason who stimulated and led a small group to become a travelling club which over the years has played a role in international surgery.

His activities were not confined to Newcastle: before the war wherever he discovered an area in which the surgical services for the treatment of tuberculosis were deficient, he travelled far and wide to develop them. As a Northumbrian his contacts with Scandinavia were able to develop freely, and, with his happy marriage to one of Norwegian birth, his value as surgical ambassador was retained to his last days.

During the war his importance as a thoracic surgeon took him away from a life at sea in the Navy, but it was during those war years

- that he recruited and developed his unit into one of the great cardiothoracic centres of the country. With the advent of heart surgery he and his team were well in the van of progress and thanks to his teachings the reputation of Shotley Bridge continues at its high level.

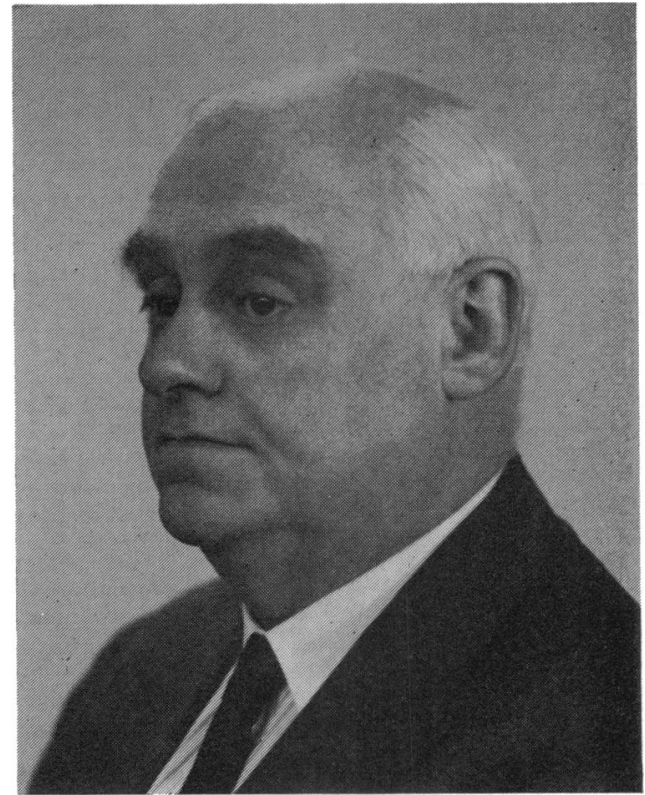

George Mason was a large man in all ways. Big in build and stature, grand in friendship and generosity, straight spoken - at times blunt and intolerant of slackness or inefficiency. He was also a man of affairs with a shrewd outlook, but the outstanding feature of his character was the absolute trust that everyone had in his integrity. He was a man who inspired affection and many were the friends who visited him for the delight of his company and of his wife's when he retired into the countryside he loved so well.

Thomas Holmes Sellors 